\title{
AN EMPIRICAL INVESTIGATION ON THE EMPLOYERS AND EMPLOYEES PERCEPTION OF E-LEARNING
}

\author{
Dr. Sourbhi Chaturvedi \\ Dean and Professor, Ganpat University, Gujarat, India
}

\begin{abstract}
The ferocity of Covid 19 has affected all of us. There has been a critical impact on the social and economic lives worldwide. There has been a revolution happened in the organizations in terms of how employees work. Even before the current crisis, changing technologies and new ways of working were disrupting jobs and the skills employees need to do them. Agrawal et.al. (2020) estimated that 14 percent of the global workforce would have to acquire new skills by 2030 because of automation and artificial intelligence.
\end{abstract}

The paper investigates the the Employers and Employees perception of ELearning. Results showed that E-Learning is perceived as a challenge by the employers of all sectors on the dimensions six dimensions of eLearning

Key words: eLearning, Conducive, Adaptive, Purposeful, Observant, Comprehensible and Proactive.

Cite this Article: Sourbhi Chaturvedi, An Empirical Investigation on the Employers and Employees Perception of E-Learning, International Journal of Management, 11(12), 2020, pp. 2399-2410.

http://iaeme.com/Home/issue/IJM?Volume=11\&Issue=12

\section{INTRODUCTION}

Globalization, competition, and labor shortages cause the employees to work longer, harder, and travel more than previous generations did. Knowledge workers require greater flexibility at the workplace. At the same time, they require more autonomy and accountability in their jobs and dislike close supervision. They have contemporary orientation to time and space, believing that as long as the work gets done on time, it is not imperative where or when it gets done. They also want some prospects to allocate time for learning. Contemporary learning and methods need to replicate these changes in the lifestyle. The corporations face major challenges in keeping their workforce updated and competent therefore, training has become a continuous process rather than a discrete event. Job intricacy has also increased as more technical and sophisticated systems are utilized that permits tailor made products for the customer. The increased use of technology requires highly trained personnel to design and 
operate these systems. Training is essential to increase the skill level, improve the resourcefulness and enhance the adaptability of the employees.

Superior digital networks at lower costs, coupled with advances in the use of server and other delivery technologies hold significant potential to increase the accessibility, affordable and efficient training options. The cost of technology supported training are decreasing significantly because of improved tools for creating training program that often can be used by subject matter experts without the requirement of programming expertise. The supply of off-the-shelf technology supported training products delivered through multimedia, Internet/Intranet and business TV is growing. Gone are the days when trainers and tutors used to solely rely on conventional methods of training and instruction. Today, they are optimistic to use more than one medium to deliver their training to make learning more effective. ELearning is now broadly accepted as a feasible learning method across corporate training and higher education. Synchronous E-Learning encompasses same-time interaction independent of location, while asynchronous E-Learning includes any situation where learners are dispersed in time and location.

The of employer under section 2(e) of the Provident Funds Act means - (i) in relation to an establishment which is a factory, the owner or occupier of the factory, including the agent of such owner or occupier, the legal representative of a deceased owner or occupier and where a person has been named as manager of the factory. (ii) in relation to any other establishment, the person who, or the authority which has the ultimate control over the affairs of the establishment, and where the said affairs are entrusted to a manager, managing director or managing agent. While, Employees is a person who is hired to provide services to a company on a regular basis in exchange for compensation and who does not provide these services as part of an independent business. The term employee under section 2(f) of the Provident Funds Act means any person who is employed for wages in any kind of work, manual or otherwise or in connection with the work of an establishment, and who gets his wages directly or indirectly from the employer. Bakar et al., (2003) while studying the association between training and three types of organizational commitment i.e., affective, normative and continuance commitment among white collar workers in Malaysia, found that availability of training, support for training, motivation to learn was positively associated with affective and normative commitment and not with continuance commitment. The training environment and benefits of training were correlated with all the three types of commitment. Age and tenure were positively correlated to affective commitment i.e., older employees were more attached to organization they were working for. Similarly, gender and race had no effect on commitment while education had negative relationship with continuance commitment. Francis et al., (2000) suggested that there was a significant impact of different types of training on the mobility expectations of workers. It was found that overall training had no impact on mobility in three out of every five cases; the remaining cases were split equally in those where training increases and those where it decreases mobility. The training sponsored by firms was more likely to lead to lower mobility when it is less transferable to other firms and where training objectives include increasing the identification of the employees' objectives with corporate objectives.

Harris (1995) in a survey of the American Directors of Human Resources and Training Programs recommended computer-based technology and multimedia as an effective method of training. He opined that most of the companies resort to traditional classroom training on account to its being more cost effective and longer life span not realizing that computer based technology is a long term investment that can save both time and money. Dutton et al., (2002) found that online students were older, more committed to responsibilities such as work and children and were likely to have greater experience working with computers. These students 
were less likely to be seeking traditional undergraduate degrees and had the same level of motivation to complete the course as traditional undergraduate students. According to Triandis et al., (1988), countries with individualism culture have higher acceptability of ELearning as compared to the countries with collectivism culture. Sweeney and Ingram (2001) evaluated learning preferences for tutorials offered in face to face versus the web. While web based approaches were seen as more innovative and enjoyable, the face to face tutorials were seen as more effective learning environments by the students.

\section{OBJECTIVE}

Objective 1. To identify the perceptual gaps between the employers and the employees of different sectors.

Objective 2. To identify the perceptual gaps between the employers and the employees of different sectors on the dimensions of E-Learning.

\section{RESEARCH METHODOLOGY}

\subsection{The Study}

The purpose of the study was to explore the dimensions of E-Learning perceived important by the employers and the employees of various industrial sectors namely manufacturing, financial services, education, information technology (IT) and other services. The study is an attempt to understand which dimensions of E-Learning are perceived as the challenges and which are perceived as opportunities by the employers and the employees of different industrial sectors. The study was carried out in Indore, Bhopal, Mumbai, Ahmedabad, Delhi, Noida, Bangalore and Hyderabad taking them as representative cities of Central, West, North and South India.

\subsection{The Design}

The extraneous variables, such as casual responses, faking, experience, functional area, computer literacy and education were controlled through randomization and elimination.

Table 1

\begin{tabular}{|l|l|l|l|l|l|}
\hline $\begin{array}{l}\text { Industry } \\
\text { Sector }\end{array}$ & Manufacturing & $\begin{array}{l}\text { Financial } \\
\text { Services }\end{array}$ & Education & $\begin{array}{l}\text { Information } \\
\text { Technology }\end{array}$ & $\begin{array}{l}\text { Other } \\
\text { Services }\end{array}$ \\
\hline Employer & A & B & C & D & E \\
\hline Employee & F & G & H & I & J \\
\hline
\end{tabular}

The ten subgroups in the research design were as follows:

$\mathrm{A}=$ the employers of Manufacturing Sector.

$\mathrm{B}=$ the employers of Financial services Sector.

$\mathrm{C}=$ the employers of Education Sector.

$\mathrm{D}=$ the employers of Information Technology Sector.

$\mathrm{E}=$ the employers of Other services.

$\mathrm{F}=$ the employees of Manufacturing Sector.

$G=$ the employees of Financial Services Sector.

$\mathrm{H}=$ the employees of Education Sector.

$\mathrm{I}=$ the employees of Information Technology Sector.

$\mathrm{J}=$ the employees of Other services. 


\subsection{The Tools}

The tool was distributed personally to the subjects and they were asked to fill up their responses on their own with universal instructions given to all on the title page of the instrument. 44 items in the tool were presented on a five point Likert scale and administered on a sample of 300 respondents: the employers and the employees of manufacturing, financial services, education, information technology and other services. After collecting the data, further analysis was done to eliminate the weak or insignificant items by measuring internal consistency through item-total correlation. One item was found to be insignificant and was therefore, dropped. The remaining 43 items were again subjected to item-total correlation. None of the items indicated to be insignificant. The reliability of the scale was determined by the split-half method corrected for full length by applying Spearman Brown Prophecy formula on the data collected from the sample of 300 subjects. The reliability coefficient was found to be 0.91 . The validity for the scale was 0.95 . After item-total correlation the items whose correlation value exceeded .198, were subjected to factor analyses using Statistical Package for Social Sciences to identify factors and dimensions. In the first order factor analysis fourteen factors emerged, Aptness, Appraisal, Attuneness, Empowerment, Accessible, Futuristic, Interactive, Learner focused, Optimal utilization, Explicit, Flexible, Congenial, Innovation and Updation. These factors were subjected to second order factor analysis to identify the dimensions. The dimensions were Conducive, Adaptive, Purposeful, Comprehensible, Observant and Proactive. To understand the perceptual differences in various study groups, t-test was used on the dimensions identified.

\section{Problem 1: do the employers and the employees of different sectors differ in their perception of E-Learning?}

$\mathrm{H}_{01}$ : there is no significant difference in the perception of E-Learning between the employers and the employees of manufacturing sector.

$$
\begin{aligned}
& \text { A }(\mathbf{X}=155.85) \\
& F(X=160.33)
\end{aligned}
$$

The null hypothesis is accepted $(\mathrm{t}=-0.88)$

$H_{02}$ : there is no significant difference in the perception of E-Learning between the employers and the employees of financial services.

$\mathrm{B}(\mathbf{X}=156.62)$

$\mathrm{G}(\mathbf{X}=163.57)$

The null hypothesis is accepted $(\mathrm{t}=-1.35)$

$H_{03}$ : there is no significant difference in the perception of E-Learning between the employers and the employees of education sector.

$\mathrm{C}(\mathbf{X}=161.19)$

$\mathrm{H}(\mathbf{X}=168.47)$

The null hypothesis is rejected $(\mathrm{t}=-2.72, \mathrm{p}>.05)$

The employers and the employees of education sector differ significantly in their perception of E-Learning. The employees of education sector perceive E-Learning as a better training medium than the employers of this sector.

$H_{04}$ : there is no significant difference in the perception of E-Learning between the employers and the employees of IT sector.

$\mathrm{D}(\mathbf{X}=168.38)$

I $(\mathbf{X}=166.09)$ 
The null hypothesis is accepted $(\mathrm{t}=0.69)$

$H_{05}$ : there is no significant difference in the perception of E-Learning between the employers and the employees of other services.

$\mathrm{E}(\mathbf{X}=157.59)$

$\mathrm{J}(\mathbf{X}=160.47)$

The null hypothesis is accepted $(\mathrm{t}=-0.70)$

Problem 2: do the employers and the employees of different sectors differ on the dimension Conducive of E-Learning?

$H_{06}$ : there is no significant difference in the perception of E-Learning between the employers and the employees of manufacturing sector on the dimension Conducive.

$\mathrm{A}(\mathbf{X}=39.71)$

$\mathrm{F}(\mathbf{X}=39.95)$

The null hypothesis is accepted $(\mathrm{t}=-0.17)$

$H_{07}$ : there is no significant difference in the perception of E-Learning between the employers and the employees of financial services sector on the dimension Conducive.

$\mathrm{B}(\mathbf{X}=39.89)$

$\mathrm{G}(\mathbf{X}=40.21)$

The null hypothesis is accepted $(\mathrm{t}=-0.25)$

$H_{08}$ : there is no significant difference in the perception of E-Learning between the employers and the employees of education sector on the dimension Conducive.

$\mathrm{C}(\mathbf{X}=41.61)$

$\mathrm{H}(\mathrm{X}=42.80)$

The null hypothesis is accepted $(\mathrm{t}=-1.16)$

$H_{09}$ : there is no significant difference in the perception of E-Learning between the employers and the employees of IT sector on the dimension Conducive.

$\mathrm{D}(\mathbf{X}=43.7)$

I $(X=44)$

The null hypothesis is accepted $(\mathrm{t}=-0.32)$

$H_{010}$ : there is no significant difference in the perception of E-Learning between the employers and the employees of other services on the dimension Conducive.

$\mathrm{E}(\mathbf{X}=42.59)$

$\mathrm{J}(\mathbf{X}=39.59)$

The null hypothesis is accepted $(\mathrm{t}=1.85)$

Problem 3: do the employers and the employees of different sectors differ on the dimension Adaptive of E-Learning?

H011: there is no significant difference in the perception of E-Learning between the employers and the employees of manufacturing sector on the dimension Adaptive.

$\mathrm{A}(\mathbf{X}=19.76)$

$\mathrm{F}(\mathbf{X}=20.42)$

The null hypothesis is accepted $(t=-1.10)$ 
$H_{012}$ there is no significant difference in the perception of E-Learning between the employers and the employees of financial services sector on the dimension Adaptive.

$\mathrm{B}(\mathbf{X}=19.36)$

$\mathrm{G}(\mathbf{X}=19.42)$

The null hypothesis is accepted $(\mathrm{t}=-0.05)$

$H_{013}$ : there is no significant difference in the perception of E-Learning between the employers and the employees of education sector on the dimension Adaptive.

$\mathrm{C}(\mathbf{X}=18.77)$

$\mathrm{H}(\mathbf{X}=19.09)$

The null hypothesis is accepted $(\mathrm{t}=-0.32)$

$H_{014}$ : there is no significant difference in the perception of E-Learning between the employers and the employees of IT sector on the dimension Adaptive.

$\mathrm{D}(\mathbf{X}=19.2)$

I $(\mathbf{X}=21.25)$

The null hypothesis is rejected $(\mathrm{t}=-2.70, \mathrm{p}>.05)$

The employers and the employees of IT sectors differ significantly in their perception of ELearning on the dimension Adaptive. The employees of IT sector perceive E-Learning as a better training medium on its being more Adaptive than its employers.

$H_{015}$ : there is no significant difference in the perception of E-Learning between the employers and the employees of other services on the dimension Adaptive.

$\mathrm{E}(\mathbf{X}=20.12)$

$\mathrm{J}(\mathbf{X}=19.65)$

The null hypothesis is accepted $(\mathrm{t}=1.07)$

Problem 4: do the employers and the employees of different sectors differ on the dimension Purposeful of E-Learning?

$H_{016}$ : there is no significant difference in the perception of E-Learning between the employers and the employees of manufacturing sector on the dimension Purposeful.

$\mathrm{A}(\mathbf{X}=29.66)$

$\mathrm{F}(\mathbf{X}=31.52)$

The null hypothesis is accepted $(\mathrm{t}=-1.50)$

$H_{017}$ : there is no significant difference in the perception of E-Learning between the employers and the employees of financial services sector on the dimension Purposeful.

$\mathrm{B}(\mathbf{X}=29.94)$

$\mathrm{G}(\mathbf{X}=30.42)$

The null hypothesis is accepted $(\mathrm{t}=-0.63)$

$H_{018}$ : there is no significant difference in the perception of E-Learning between the employers and the employees of education sector on the dimension Purposeful.

$\mathrm{C}(\mathbf{X}=32.14)$

$\mathrm{H}(\mathbf{X}=30.28)$

The null hypothesis is accepted $(\mathrm{t}=1.92)$

$H_{019}$ : there is no significant difference in the perception of E-Learning between the employers and the employees of IT sector on the dimension Purposeful.

$\mathrm{D}(\mathbf{X}=33.45)$ 
I ( $\mathbf{X}=36.1)$

The null hypothesis is rejected $(\mathrm{t}=-2.69, \mathrm{p}>.05)$

The employers and the employees of IT sector differ significantly in their perception on the dimension Purposeful of E-Learning. The employees of this sector perceive E-Learning as a better training medium on its being more Purposeful than its employers.

$H_{020}$ : there is no significant difference in the perception of E-Learning between the employers and the employees of other services on the dimension Purposeful.

$\mathrm{E}(\mathbf{X}=30.47)$

$\mathrm{J}(\mathbf{X}=30.76)$

The null hypothesis is accepted $(\mathrm{t}=-0.20)$

Problem 5: do the employers and the employees of different sectors differ on the dimension Comprehensible of E-Learning?

$H_{021}$ : there is no significant difference in the perception of E-Learning between the employers and the employees of manufacturing sector on the dimension Comprehensible.

$\mathrm{A}(\mathbf{X}=15.66)$

$\mathrm{F}(\mathbf{X}=16.42)$

The null hypothesis is accepted $(\mathrm{t}=-1.22)$

$H_{022:}$ there is no significant difference in the perception of E-Learning between employers and the employees of financial services sector on the dimension Comprehensible.

$\mathrm{B}(\mathbf{X}=13.73)$

$\mathrm{G}(\mathbf{X}=14.52)$

The null hypothesis is accepted $(\mathrm{t}=-0.76)$

$H_{023}$ : there is no significant difference in the perception of E-Learning between employers and the employees of education sectors on the dimension Comprehensible.

$\mathrm{C}(\mathbf{X}=16.66)$

$\mathrm{H}(\mathbf{X}=16.38)$

The null hypothesis is accepted $(\mathrm{t}=0.79)$

$H_{024}$ : there is no significant difference in the perception of E-Learning between employers and the employees of IT sectors on the dimension Comprehensible.

$\mathrm{D}(\mathbf{X}=16.25)$

I $(\mathbf{X}=16.15)$

The null hypothesis is accepted $(\mathrm{t}=0.27)$

$H_{025}$ : there is no significant difference in the perception of E-Learning between employers and the employees of other services on the dimension Comprehensible.

$\mathrm{E}(\mathbf{X}=15.29)$

$\mathrm{J}(\mathbf{X}=15.12)$

The null hypothesis is accepted $(\mathrm{t}=0.42)$

Problem 6: do the employers and the employees of different sectors differ on the dimension Observant of E-Learning?

$H_{026:}$ there is no significant difference in the perception of E-Learning between employers and the employees of manufacturing sectors on to the dimension Observant.

$\mathrm{A}(\mathbf{X}=24.85)$ 
$\mathrm{F}(\mathbf{X}=25.90)$

The null hypothesis is accepted $(\mathrm{t}=-1.09)$

$H_{027}$ : there is no significant difference in the perception of E-Learning between the employers and the employees of financial services sectors on the dimension Observant.

$\mathrm{B}(\mathbf{X}=26.15)$

$\mathrm{G}(\mathbf{X}=26.73)$

The null hypothesis is accepted $(\mathrm{t}=-0.38)$

$H_{028}$ : there is no significant difference in the perception of E-Learning between the employers and the employees of education sectors on the dimension Observant.

$\mathrm{C}(\mathbf{X}=26.09)$

$\mathrm{H}(\mathbf{X}=24.90)$

The null hypothesis is accepted $(\mathrm{t}=1.34)$

$H_{029}$ : there is no significant difference in the perception of E-Learning between the employers and the employees of IT sectors on the dimension Observant.

$\mathrm{D}(\mathbf{X}=27.75)$

I $(\mathbf{X}=26.5)$

The null hypothesis is accepted $(\mathrm{t}=1.11)$

$H_{030}$ : there is no significant difference in the perception of E-Learning between the employees and the employers of other services on the dimension Observant.

$\mathrm{E}(\mathbf{X}=25.88)$

$\mathrm{J}(\mathbf{X}=25.94)$

The null hypothesis is accepted $(\mathrm{t}=-0.08)$

Problem 7: do the employers and the employees of different sectors differ on the dimension Proactive of E-Learning?

$H_{031}$ : there is no significant difference in the perception of E-Learning between the employers and the employees of manufacturing sector on the dimension Proactive.

$\mathrm{A}(\mathbf{X}=30.95)$

$\mathrm{F}(\mathbf{X}=30.85)$

The null hypothesis is accepted $(\mathrm{t}=.09)$

$H_{031}$ : there is no significant difference in the perception of E-Learning between the employers and the employees of financial services sector on the dimension Proactive.

$\mathrm{B}(\mathbf{X}=31.57)$

$\mathrm{G}(\mathbf{X}=31.57)$

The null hypothesis is accepted $(\mathrm{t}=0)$

$H_{032}$ : there is no significant difference in the perception of E-Learning between the employers and the employees of education sector on the dimension Proactive.

$\mathrm{C}(\mathbf{X}=32.09)$

$\mathrm{H}(\mathbf{X}=31.66)$

The null hypothesis is accepted $(\mathrm{t}=0.55)$

$H_{033}$ : there is no significant difference in the perception of E-Learning between the employers and the employees of IT sector on the dimension Proactive.

$\mathrm{D}(\mathbf{X}=31.25)$ 
$\mathrm{I}(\mathbf{X}=31.2)$

The null hypothesis is accepted $(\mathrm{t}=0.09)$

$H_{035:}$ there is no significant difference in the perception of E-Learning between the employers and the employees of other services on the dimension Proactive.

$\mathrm{E}(\mathbf{X}=30.82)$

$\mathrm{J}(\mathbf{X}=31.24)$

The null hypothesis is accepted $(\mathrm{t}=-0.44)$

\section{CONCLUSION}

Employers and Employees of different sectors were compared on seven problems and 35 null hypotheses. Out of which 3 were rejected and 32 were accepted. E-Learning is perceived as a challenge by the employers of all sectors on the dimensions six dimensions namely Conducive, Adaptive, Purposeful, Observant, Comprehensible and Proactive. Employees of education sector perceive E-Learning as a better training medium than the employers of its sector. The employees of IT sector perceive E-Learning as a better training medium on it being more Adaptive and Purposeful than the employers of IT sector. E-Learning is perceived as an opportunity for training by the employee of IT sector on the dimension Adaptive and Purposeful.

\section{IMPLICATIONS}

Sambrook (2003) found that the employers had positive attitudes to training in general, but were less positive about E-Learning. A survey of the employers suggested that 12 per cent were using E-Learning, 28 per cent were eager to do so; the remaining 60 did not express a preference for introducing E-Learning. Evans and Louise (2002) stated that sales training is one of the most preferred areas considered by organizations for the implementation of ELearning. IT/Telecoms sector confirmed that E-Learning had a positive impact on sales, followed by Manufacturing/ Retail sector and Financial services. Training is no longer seen as an extravagance but as necessity to compete with competitors. E-Learning is Purposeful for the employers as it provides correct and updated content at optimum cost and reduces the time spent by the employees away from the job. Hicks (2000) reported that companies can save up to 70 percent of their training budget while instituting E-Learning courses within their firms. Purposeful on its being a facilitator in updating their skill sets. The present day dynamic environment has made the employees more cautious about their skills and knowledge sets to remain updated and employable. E-Learning facilitates this updation by providing an opportunity through virtual learning. E-Learning decreases inhibition and gender barrier and promotes greater inquisitiveness, expressiveness, risk taking and social connectedness (McGrath, 1998).

Webster (2001) reported that learners had 60 percent faster learning curve as compared to their classroom counterparts. Learners' needs were also driving forces in E-Learning. In the manufacturing sector the nature of the job is activity oriented, conceptualization of activities and interaction would not be of much help to train the employees for the job. The employees learn on the pedagogical design of scenario based learning. The online courses are more suitable to teach basic concepts rather than for developing complex skills (Hunt, 2002). The Chartered Management Institute and Centre for Applied Human Resource Research (2007) reported that 43 percent of the respondents in manufacturing sector were resistant to ELearning because they perceived that it lacked human touch. It also confirmed that just 11 percent of senior managers in the manufacturing sector had participated in a structured ELearning programme. Many firms are highly specialized like manufacturing, financial 
services and other services, which makes the development of learning materials expensive and hence, commercially uninteresting. In the financial services sector interactivity is discouraged due to the high risk of the corporate data being disclosed. Therefore, commitment from the top management was the most essential ingredient for successful E-Learning implementation.

According to Gulati et al., (2001), E-Learning helped the learner to acquire the information from several sources like the internet, his or her own prior experience, collaboration from other learners, references and other sources of expertise. This was a Constructivist approach which was more learner-focused. The emphasis was on creating an environment in which the learners can actively create their own meaning in the context, rather than passively absorb knowledge structures created by the instructor. In this approach, the instructor's role moved away from being the sole source of information towards being a coach and originator of the resources. E-Learning's ability to provide functionalities for learning control to transfer from instructor to learner act as a challenge for the education sector. The lack of synergy between departments made it further challenging to the employees of education sector. The employees of other services are not technologically sound and need not update their skill sets as quickly as the employees of IT sector. Martocchio (1994) suggested that the learners with lower levels of computer self-efficacy were related to lower learning outcomes and had difficulty in using the computer as a learning tool. Brown (2001) found that the computer experience was positively associated with pre and post-test scores, suggesting that those with more computer experience tend to do better in E-Learning environments.

Welsh et al., (2003) concluded that the industries in which computers were widely used were more suited to effective E-Learning. As these sectors had less use of computers as compared to IT sector, therefore, IT sector has emerged as a clear adaptor of E-Learning. Financial resources helped to make learning cultures and technology infrastructures realities. Thus, financial resources were primary in creating learning experiences that provided meaningful, relevant, and authentic learning. Conducting a needs assessment, learner analysis, or usability testing could have direct and indirect financial implications. Waight et al., (2004) in their study on innovation and renewal of an E-Learning solution found that financial support allowed the E-Learning team to seek a research partnership to help them learn and improve their E-Learning solution. The employers of the other sectors perceived E-Learning as less Purposeful because the initial investment incurred to set up the training infrastructure would not help them reduce the initial cost of training. Moreover, they would have to face lot of cultural resistance within the organization.

An adaptive environment modifies according to learner characteristics. E-Learning is more adaptive as it gives flexibility to learn, update and present the content of the training program according to the learners' requirements. The training program can be used by many learners according to their own learning styles. Behavioral or Objectivist Model includes traditional classroom training where the instructor controls the content and pace of learning. Learners are passive and learning is said to occur in isolation. While, in Cognitive or Constructivist model, the learner holds the responsibility for learning, controls the pace of learning and the instructor is the facilitator providing support to construct knowledge. ELearning is based on Cognitive or Constructivist model. According to Porter (1997), the greatest strength of E-Learning lies in the different formats by which information can be presented. Different formats allow to meet different learners' preferences. Identifying which method or combination of methods is best suited for a given topic or course, requires careful analysis of curriculum design, delivery technologies and instructor and learner requirements. Sims and Hedberg (1995) found that in addition to self-pacing if the learners are given the control over various instructional elements such as the sequence of instructional material, the content of instruction (e.g., which topics to study), and the amount of instruction during 
training, small but positive impact was seen on the learning outcomes. Control over the learning process empowers the learners and make them an E-Learning enthusiast.

Estamound (1995) pointed out self-directed learning is a desirable trait and function not only for learners but also for instructional facilitator and the sponsoring institution. Identifying which method or combination of methods was best suited for a given topic or course, required careful analysis of curriculum design, delivery technologies and instructor and learner requirements. To accommodate the needs of different learners in the training program would make the dimension Adaptive of E-Learning a challenge for the employers of IT sector. Welsh el al., (2003) enumerated that most of the people learned effectively from ELearning program. The training cost could be reduced if there were large number of learners geographically dispersed and if the course was to be repeated several times.

Vaughan et al., (2004) reported that E-Learning would help lifelong learning as it would be accessing learning at will. The self paced accessibility would discipline the learner and give him necessary motivation to learn. Macpherson et al., (2003) cited that the flexibility tended to focus on two main issues: flexibility in delivery and in pace and distribution of learning. The flexibility of delivery offered organizations the ability to deliver consistent learning experiences independent of time and place. This offered great advantage to a geographically-dispersed workforce, for those employees working in non-standard hours and who worked from a home base. Different languages, education systems, learning/teaching styles, government regulations, and infrastructures were examples of these variations. To adapt training to multicultural settings required a new paradigm that included an understanding of the deeper psychology of culture and the unique differences culture brought to a global workplace (Kemper, 1998).

\section{REFERENCES}

[1] Agrawal Sapana, Smet Aaron De , Poplawski Pawel, Reich Angelika (2020), a partner in the Zurich office. Beyond hiring: How companies are reskilling to address talent gaps. https://www.mckinsey.com/business-functions/organization/our-insights/beyond-hiring-howcompanies-are-reskilling-to-address-talent-gaps\#

[2] Bakar, Raida Abu and Ahmad, Kamarul Zaman (2003). The Association of Training and Organization Commitment among White Collar Workers in Malayaia. International Journal of Training and Development, 7:3 ISSN 1360-3736.

[3] Brown, K. (2001). Using Computers to Deliver Training: Which the Employers Learn and Why? Personnel Psychology, 54, 271-296.

[4] Chartered Management Institute and Centre for Applied Human Resource Research (2007). Manufacturing Managers Should Use Internet More. http://www.Manufacturingtalk.com /news/ced/ced130.html).

[5] Dutton, J.; Dutton, M. and Perry, J. (2002). How do Online Students Differ from Lecture Students? Journal of Asynchronous Learning Networks, 6.

[6] Estamound, D.V. (1995). Alone but Together. Adult Distance Study through Computer Conferencing. New York : Basic Books.

[7] Evans, Baldwin Kay and Louise, Jaggs (2002). Research Claims ELearning Has a Positive Impact on Sales. (http://www.trainingpressreleases.com/newsstory.asp?newsid =226).

[8] Francis, Green; Felstead, Alan; Mayhew, Ken and Pack, Alan (2000). The Impact of Training on Labour Mobility: Individual and Firm-Level Evidence from Britain. British Journal of Industrial Relations, 38(2).

[9] Gulati, V. P. and Sivakumaran, M. V. (2001). E-Learning in Banking: Perspectives and Initiatives. (http://www.cdac.in/html/pdf/session.3.3.pdf). 
[10] Harris, Kimberley J. (1995). Training Technology in the Hospital Industry: A Matter of Effectiveness. International Journal of Contemporary Hospitality Management, 7(6), 24-29.

[11] Hicks, S. (2000). Evaluating E-Learning. Training and Development, 54(12).

[12] Hunt, Justin (2002). Putting the 'Wow' Back to E-Learning. The Guardian Supplement Business Solutions, 6-7, Nov 28.

[13] Kemper, C. (1998). Global Training's Critical Success Factors. Training and Development, 35-37.

[14] Martocchio, J. J. (1994). Effects of Conceptions of Ability on Anxity, Self-Efficacy and Learning in Training. Journal of Applied Psychology, 79, 819-25.

[15] McGrath, C. (1997-98). A New Voice on Interchange: Is it Talking or Writing? Implications for the Teaching of Literature. Journal of Educational Technology Systems, 26, 291-297.

[16] Macpherson, A, Elliot M, Harris I, Homan G (2003). Reflections of ELearning: Pedagogy and Practice in the Corporate Sector. Working Paper (WP03/01), Manchester: Manchester Metropolitan University Business School Working Paper Series.

[17] Porter, L. R. (1997). Creating Virtual Classroom: Distance Learning With the Internet. New York: J. Wiley and Sons.

[18] Sambrook, S. (2003). E-Learning in Small Organizations. Education and Training, 45(8/9), 506-516.

[19] Sims, R., and Hedberg, J. (1995). Dimensions of Learner Control: A Reappraisal for Interactive Multimedia Instruction. In J. M. Pearce and A. Ellis (Eds.), Learning With Technology. Proceedings of the Twelfth Annual Conference of the Australian Society for Computers in Learning in Tertiary Education: 468-475. Melbourne, Australia.

[20] Sweeney, J. and Ingram, D. (2001). A Comparison of Traditional and Web-Based Tutorials in Marketing Education: An Exploratory Study. Journal of Marketing Education, 23(1), 55-62.

[21] Triandis, H. C.; Bontempo, R. and M. Villareal (1988). Individualism and Collectivism: Cross-Cultural Perspectives on Self-In-Group Relationships. Journal of Personality and Social Psychology, 53(2), 33-338.

[22] Vaughan, Kirsty and Macvicar, Anna (2004). The Employees' Pre-Implementation Attitudes and Perceptions to E-Learning: A Banking Case Study Analysis. Journal of European Industrial Training, 28(5), 400-413.

[23] Webster, R. (2001). E-Learning Takes Workers out of Classroom. New Orleans City Business, 21(40).

[24] Welsh, E.; Wanberg, C.; Brown, K. and Simmering, M. (2003). ELearning: Emerging Issues, Empirical Results and Future Directions. International Journal of Training and Development, 8(4), 245-258.

[25] Waight, C.L.; Downey, S.; Wentling, T. and Arvidson, R. (2004). Innovation and Renewal of an E-Learning Solution within Insurance Corporation. Performance Improvement Quarterly, 17(4), 50-65. 